\title{
POST CAESARIAN VAGINAL OMENTAL PROLAPSE: A RARE CASE REPORT
}

Asavari Ashok Bachhav' ${ }^{1}$, Juzer Ibrahim Fidvi²

\section{HOW TO CITE THIS ARTICLE:}

Asavari Ashok Bachhav, Juzer Ibrahim Fidvi. "Post caesarian vaginal omental prolapse: a rare case report". Journal of Evolution of Medical and Dental Sciences 2013; Vol. 2, Issue 47, November 25; Page: 9228-9230.

ABSTRACT: Vaginal evisceration following lower segment caesarian section is a rare occurrence. There is no documented case report available although omental prolapse following third stage of labour have been reported due to old uterine perforation following multiple curettage and uterine rupture in multi gravid patients respectively. This is a life threatening complication diagnosed only after a high index of suspicion and a thorough clinical examination. We report a case of post caesarian vaginal omental prolapse in a primi gravida.

CASE REPORT: A 26 year old primi gravida was admitted with us from 34 weeks onwards as a case of hypothyroidism with mild pre-eclampsia for observation and further in-patient management. On admission, her blood pressure was $150 / 100 \mathrm{~mm} \mathrm{Hg}$, urine albumin was +2 by dipstick method with no premonitory signs or symptoms. On general examination: bilateral pedal edema with facial puffiness was present and deep tendon reflexes were normal. On per abdominal examination: uterus was 30-32 weeks gestation with mild abdominal ascites. She had been diagnosed as hypothyroid in her first trimester and was on thyroxine for the same. She was started on antihypertensives. Laboratory investigations for pre-eclampsia were within normal limits. Obstetric ultrasonography showed evidence of fetal growth retardation with oligohydramnios with AFI of 4-5. Doppler ultrasound showed bilateral uterine artery notching with no evidence of utero-placental insufficiency. Patient was managed conservatively with steroids being given for fetal lung maturity, weekly investigations being monitored and blood pressure stabilized at 140/90 mm Hg.

She went into spontaneous labour at 36 weeks of gestation and liquor being thick meconium stained, a decision for emergency LSCS in view of severe fetal distress was taken. Lower segment caesarian section was done with midline infraumbilical incision taken in view of severe fetal distress being done in late first stage of labour and a preterm, FGR male child was delivered by vertex. Mild to moderate ascites was present. As the LSCS was done in late first stage of labour, there was an extension of the uterine incision on the right side to the lower segment. Consequently, the right sided uterine artery ligation was done and hemostasis satisfactorily achieved. The uterus was sutured in two layers with the visceral and parietal peritoneum being closed separately followed by abdominal closure in layers. The neonate required urgent resuscitation and was admitted to the NICU for further management. In early post operative period patient had pyrexia for which high grade antibiotics were started. Despite antibiotic coverage, patient developed a full length wound gape on day 10 . The wound gape was managed conservatively with daily wound dressing with full asepsis and antibiotic coverage according to microbial sensitivity. The wound healed satisfactorily and the patient was discharged on day 25.0n discharge, her blood pressure was within normal limits and was continuing thyroxine.

Patient followed up after 3 months of surgery with complaints of something coming out of vagina since one week which increased on straining and was not reposited on rest (Fig .1). There was no history of any foul smelling discharge or fever following discharge from hospital. On 
examination, the patient was apprehensive but her vitals were stable. General physical examination and systemic examination was normal. On per abdomen examination, the abdomen was soft with no mass or tenderness and hernial orifices were normal. Speculum examination revealed an irregular, fleshy, thick mass coming through the cervix. It was $5 \mathrm{~cm} \times 1 \mathrm{~cm}$ in size and did not bleed on touch. Vaginal examination showed same mass/growth palpable on gloved finger with slight bleeding. No abnormality was detected on per rectal examination. Routine laboratory investigations were normal except for a decreased hemoglobin of $8 \mathrm{gm} \%$ for which one pint of blood transfusion was given. Ultrasonography of pelvis and abdomen showed increased endometrial thickness with no other abnormality in the pelvis and abdomen. Decision for examination under anaesthesia/SOS exploratory laparotomy was taken.

Intraoperatively, a tongue shaped fleshy mass simulating omentum,lying in the vagina, protruding from the cervix was seen. The mass was gently pulled down till a normal looking omentum came out which was identified. Decision for exploratory laparotomy was taken. Intraoperatively, multiple thick bands of adhesions were present. After sharp and blunt dissection, the uterus was visualized and on the right posterior aspect of the isthmus,a rent of $0.5 \times 0.5 \mathrm{~cm}$ was visualized through which the omentum earlier adherent had gained entry to the uterine cavity and herniated through the vagina(Fig. 2). It was postulated to be the site of right uterine artery ligation.The omentum was gently retracted through the opening and was transfixed and resected. The rent was closed with interrupted sutures with delayed absorbable vicryl. The left sided ovary and tube could not be visualized due to dense adhesions and right sided ovary and tube were densely adherent to each other. The abdomen was closed in layers after confirming hemostasis. The postoperative course was uneventful. A delayed suture removal was done on day 14, the wound was healthy and the patient was discharged.

DISCUSSION: The incidence of caesarian sections in obstetric practice has undoubtedly increased in the past few years. Women are now four times more likely to have a caesarian birth than 30 years ago. There is also a wide variation in surgical techniques used worldwide and even in different hospitals. Also, the advances in neonatal care with increase in the survival rates at lower gestational ages have made caesarian section a preferred option over preterm birth and the resultant neonatal morbidity and mortality.

In our case, the pregnancy being a high risk with preterm labour and severe fetal distress made a caesarian section an obvious choice for mode of delivery. The intra operative complication was satisfactorily managed by unilateral uterine artery ligation.

Bilateral uterine artery ligation (O'Leary stitch) has become the first line of management in managing PPH during laparotomy. Although primarily used for laceration of uterine arteries,it can also be used for bleeding due to other etiologies. It is preferable to internal iliac artery ligation because the uterine arteries are more readily accessible, the procedure is technically easier, and there is less risk to major adjacent vessels and the ureter. [1]

Post caesarian omental prolapse in a previously unscarred uterus is an exceedingly rare complication and no such case has been previously reported although omental prolapse following third stage of labour have been reported due to old uterine perforation following multiple curettage and uterine rupture in multi gravid patients respectively [2,3] In our patient, it was surmised that the due to the hemostatic suture, there was infarction followed by necrosis abetted by the wound 
infection that followed postoperatively. As a result, the omentum being the "guardian of the abdominal cavity" moved in to seal the uterine wound and in the process, adhesion followed by herniation through the necrosed wound followed.

Uterine artery ligation as a method of controlling traumatic PPH during caesarian section is commonly done in hospitals worldwide and is also taught to post-graduates as a routine procedure. This hitherto unknown complication brings forth to us that the procedure needs to be carefully taught with the proper technique and precautions. Also, any post operative wound infection needs to aggressively managed to prevent further complications like chronic pelvic pain, infertility and as the above case demonstrates, rare but dangerous complications like omental incarceration.

A high degree of vigil and suspicion is required in such cases for diagnosis and appropriate management of the patient to prevent further morbidities.

\section{REFERENCES:}

1. O'Leary JA.Uterine artery ligation in the control of postcaesarean hemorrhage. J Reprod Med. 1995; 40(3):189.

2. Donald E. Marsden Omentum Presenting at the Vulva After a Normal Labor and Delivery An unusual late complication of induced abortion 1984, Vol. 63, No. 3 , Pages 277-278.

3. Savita R Singhal, Suresh K Singhal, Poonam Gupta Bowel and omentum prolapse into the vagina after third stage: An unusual presentation of ruptured uterus Acta Obstetricia et Gynecologica Scandinavica Volume 87, Issue 5, pages 577-578, May 2008.
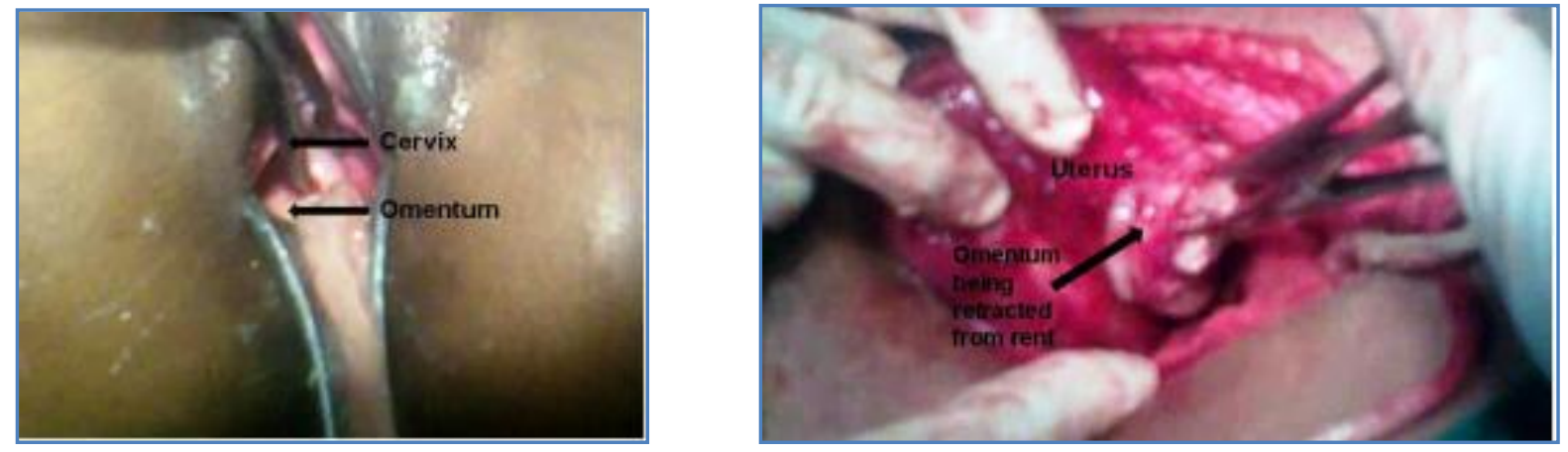

\section{AUTHORS:}

1. Asavari Ashok Bachhav

2. Juzer Ibrahim Fidvi

\section{PARTICULARS OF CONTRIBUTORS:}

1. Medical Officer, Department of Obstetrics and Gynaecology, Civil Hospital, Nasik, Maharashtra.

2. Professor \& HOD, Department of Obstetrics and Gynaecology, Indira Gandhi Government Medical College, Nagpur, Maharashtra, India.

\section{NAME ADDRESS EMAIL ID OF THE CORRESPONDING AUTHOR:}

Dr. Asavari Bachhav, Tulshi Hospital, Opposite Telephone Exchange, N.D. Patel Road, Nasik - 422001, Maharashtra, India.

Email - asavari.b@gmail.com

Date of Submission: 02/09/2013.

Date of Peer Review: 03/09/2013.

Date of Acceptance: 07/11/2013.

Date of Publishing: 22/11/2013 